\title{
Dynamics of mountain ice caps during glacial cycles: the case of Patagonia
}

\author{
Nick Hulton, David Sugden \\ Department of Geography, University of Edinburgh, Edinburgh EH8 9 XP, Scotland
}

\begin{abstract}
We use a time-dependent ice-cap model to predict the pattern of growth and decay of the Patagonian ice cap during a simulated glacial cycle. The purpose is to illuminate the internal system dynamics and identify thresholds of stability related to the underlying topography. This is a necessary step if former ice-cap behaviour is to be linked to climatic change. The model, which is fully described elsewhere, portrays ice extent and surface altitude at intervals of 1000-5000 years. The modelling suggests that there are two stable ice-cap states largely influenced by topography, namely, the present distribution of upland ice fields and the long, linear ice cap along the Andes as represented by the Last Glacial Maximum. Both states can coexist in equilibrium with a climate similar to that of the present day. There is a third, larger variable state in which a more extensive ice cap extends into the adjacent plains, as occurred during early Quaternary glaciations. Warmer and/or drier conditions are required to remove all these ice caps. There are five ice centres during ice-cap growth.
\end{abstract}

\section{INTRODUGTION}

The overall aim is to provide insight into the behaviour of mountain ice caps during a glacial cycle. The particular focus is on the internal system dynamics which affect the way ice caps respond to climatic change. This involves identification of thresholds in ice-cap behaviour related to the topography of the mountains, and an analysis of the sensitivity of the ice cap to climatic change at different stages of a glacial cycle. It also highlights those topographic thresholds the effects of which asymmetric, depending on whether they are associated with the growth or decay limbs of the glacial cycle. This paper explores the dynamics of the Patagonian ice cap through the use of a time-dependent glaciological model. Using a series of different assumptions we run a number of experiments to show the spatial distribution and thickness of the ice cap at various stages of a glacial cycle, and the associated changes in ice volume.

Appreciation of the internal system dynamics of a mountain ice cap is important in relating ice-cap behaviour to climatic change. Topography can encourage or suppress feedback loops in ice growth or decay by influencing glacier flow and thus the altitudinal distribution of accumulation and ablation zones (Ahlmann, 1948; Oerlemans, 1988; Payne and Sugden, 1990; Hubbard, 1997). There are three main influences of topography: the effect of the steepness of the topography on glacier flow; the altitudinal distribution of topography and its direct effect on snow accumulation; the spatial arrangement of topography and its effect on glacier drainage. Since the relationships may differ according to whether the ice cap is growing or decaying, an ice cap of a particular extent and volume may represent very different glacial and climatic conditions depending on the stage of a glacial cycle. Such behaviour, or hysteresis, has been recognised in other ice-sheet simulations (Huybrechts, 1993).

A modelling approach to the study of the dynamics of an ice cap is helpful in relating empirical evidence of former ice behaviour to glaciological theory. It is necessary to unravel topographic effects if one is to appreciate the climatic significance of moraine sequences, for example those bordering mountain foot lakes in the Chilean lake district. Here several advances of similar size have been related to the last glaciation (Porter, 1981) and to comparable advances in the Northern Hemisphere (Lowell and others, 1995); they contrast with more extensive older drifts attributed to earlier Quaternary glaciations. At first sight this would seem to point to several phases of equal climatic intensity during the last glaciation and considerably more severe conditions during earlier glaciations. On the other hand, the mountain foot position may reflect a stable position influenced more by the nature of the topography than by differences in climate (Bentley, 1996; Hubbard, 1997). A wide range of different climates could cause advances of similar magnitude. If we can disentangle how stability/threshold processes operate within a particular glacial system then it is possible to say something about how particular glaciological interpretations in the geomorphological record are related to climate.

Three ice fields exist today in higher parts of the Andes: Hielo Patagónico Norte (HPN; 46-47 S), Hielo Patagónico Sur (HPS; $\left.48-52^{\circ} \mathrm{S}\right)$ and Hielo Cordillera Darwin $(\mathrm{HCD}$; $54-55^{\circ} \mathrm{S}$ ). During full glacial episodes they coalesce to form a long narrow ice cap extending $1800 \mathrm{~km}$ along the axis of the Andes (Fig. 1). The changing distribution of the ice cap during a glacial cycle offers two particular advantages when examining the link between climate and ice-cap behaviour. First, the linear, narrow ice cap minimises the feedback effects which complicate atmosphere-ice-sheet interactions associated with former large ice sheets in the Northern Hemisphere. Secondly, the presence of the Andes provides an ideal experimental situation, in that there is a clearly defined, high and continuous topographic barrier. 


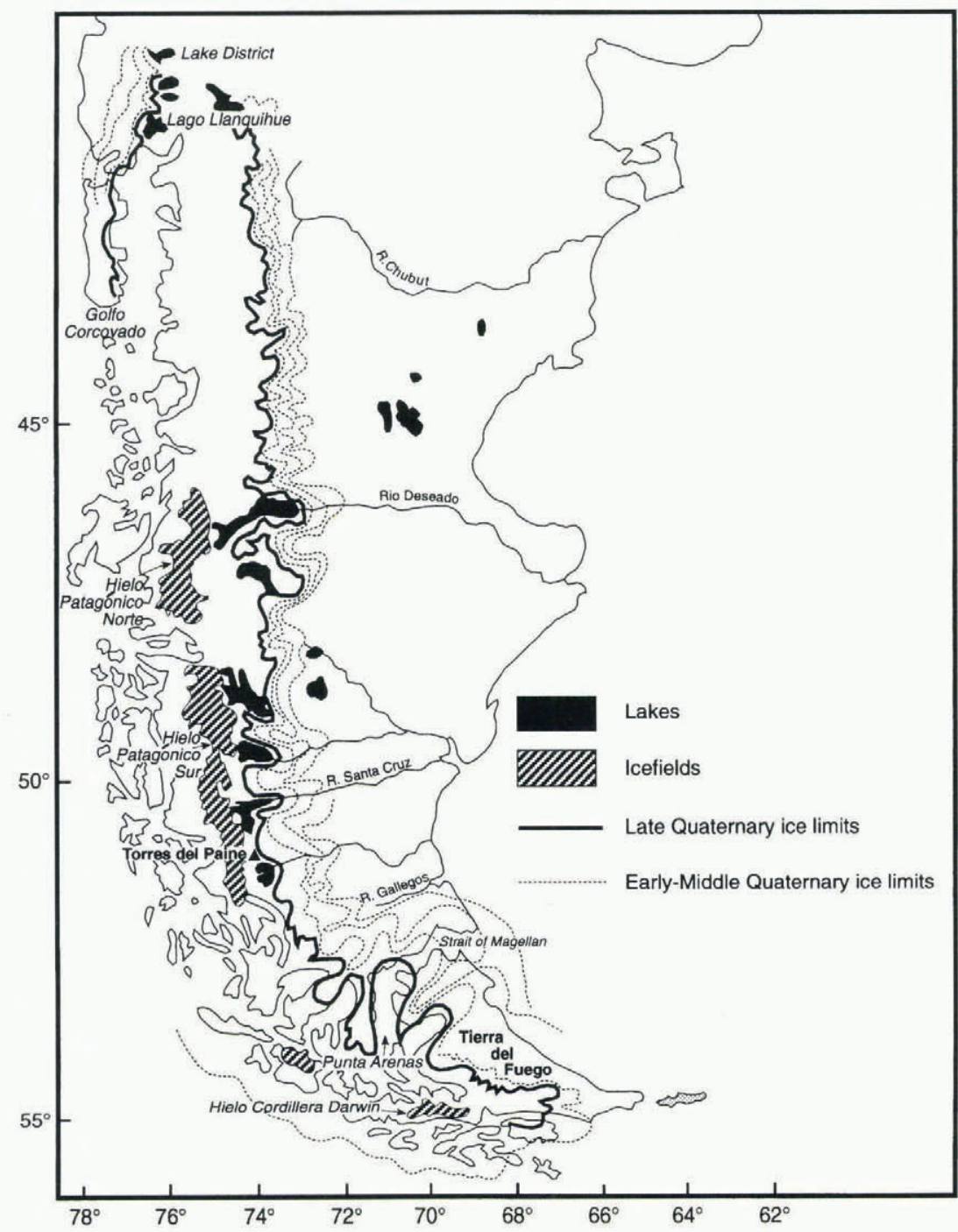

Fig. 1. Limits of the Last Glacial Maximum and early-Quaternary glaciations in Patagonia. After Clapperton (1993).

The Patagonian ice cap is in a climatically significant location since it lies athwart the Southern Hemisphere westerlies. At present, maximum precipitation at sea level is $6000-8000 \mathrm{~mm}$ and occurs in latitudes $48-52^{\circ} \mathrm{S}$, falling to $2000 \mathrm{~mm}$ to the north and south (Miller, 1976). Winds vary in both persistence and velocity in the same way; for example, at latitude $52^{\circ} \mathrm{S}$ the average daily wind speed is $12 \mathrm{~m} \mathrm{~s}^{-1}$, and velocities greater than $30 \mathrm{~m} \mathrm{~s}^{-1}$ occur each month. Mean annual temperatures, with a low seasonal range typical of a maritime climate, fall from $11.0^{\circ} \mathrm{C}$ at latitude $42^{\circ} \mathrm{S}$ to $5.5^{\circ} \mathrm{C}$ at $55^{\circ} \mathrm{S}$. The Andes, with an average altitude of 2000 $2500 \mathrm{~m}$, form a barrier to the westerlies. They introduce a sharp precipitation contrast between the excessively wet windward flank and the semi-arid eastern flank. The glaciological implication of the climatic setting is that an ice cap building up over the mountains spans latitudinal climatic zones from cool temperate in the south to warm temperate in the north. Also, there is a remarkably strong west-east gradient in the magnitude of the mass balance varying from up to $8 \mathrm{~m}$ in the maritime west to less than $0.2 \mathrm{~m}$ in the semiarid east.

\section{THE MODEL AND EXPERIMENTAL DESIGN}

The approach in this paper is to use a glaciological model to identify thresholds and stabilities in the modelled ice-cap https://doi.org/10.3189/S0260305500011976 Published online by Cambridge University Press system. We assume that the major modelled components of the system are good analogues of the real system. These are:

The mass-balance-altitude relationship.

The regional topography.

The ice-sheet form.

The ice-mass flux.

We explore the modelled system's tendency to achieve a stable state given an initial morphology and continuous steady forcing. In the experiments the general character of the mass-balance relationship stays unchanged in spite of ice-sheet growth. This is a simplification which means that the method does not permit study of the possible ways in which different ice-cap states may in themselves influence the mass-balance-altitude relationship.

The model has been described in detail by Hulton and others (1994). It is time-dependent and forced by changing the mass-balance-altitude relationship. It relies on a vertically integrated, ice-mass continuity model solved over a finite-difference grid with a resolution of $20 \mathrm{~km}$. In the original work (Hulton and others, 1994) the experiments were designed so that the model achieved an equilibrium extent comparable to that of the known limits of the Last Glacial Maximum. The match between the resulting bestfit model and reality was quite good, in that the overall di- 


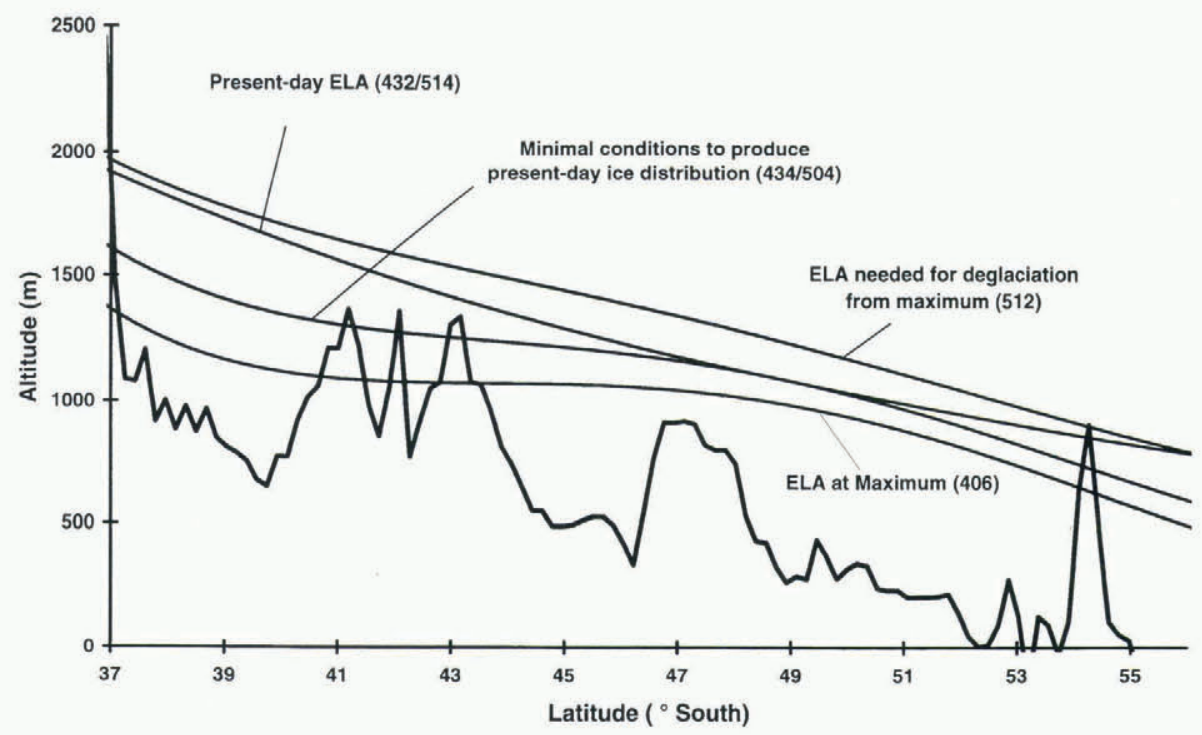

Fig. 2. Altitude of the present-day ELA (after Hulton and others (1994)) and the ELAs used in this paper. We include the ELA for the glacial maximum and for various deglaciation scenarios. Numbers in parentheses refer to particular model runs.

mensions of the ice cap and some of the larger lobes were replicated in both. Sensitivity analyses showed that the model was robust in its main conclusions. Changes in such factors as ice rheology had a modest effect on ice thickness but had little influence on ice extent. Rather, the main conclusion was that during the Last Glacial Maximum there was a differential lowering of the equilibrium-line altitude (ELA) in different latitudes (a minimum lowering compared to the present of $\sim 500 \mathrm{~m}$ at $40^{\circ} \mathrm{S}, \sim 100 \mathrm{~m}$ at $50^{\circ} \mathrm{S}$ and $\sim 250 \mathrm{~m}$ around $56^{\circ} \mathrm{S}$ ) and a northward migration of the westerlies which accentuated ELA lowering in the north and suppressed it in latitudes $46-51^{\circ} \mathrm{S}$. The experiments in the present paper are based on the same model (Hulton and others, 1994). In the growth experiments the change in ELA was introduced as a stepped function on an ice-free topography. Deglaciation was simulated by a stepped ELA rise applied to ice maximum conditions. The absolute values and their deflection from the present-day ELA are shown in Figure 2. The values of ELA depression required to simulate glacial conditions vary from latitude to latitude, and range from 100 to $500 \mathrm{~m}$. The lowering of the ELA also varies from west to east and reflects the effect of continentality, as discussed elsewhere (Hulton and others, 1994). Deglaciation is simulated by a stepped return to present-day conditions. Also shown is the lowest possible ELA consistent with the present-day glacier extent. In one experiment we apply the latter ELA to the maximum ice extent during the Last Glacial Maximum.

These simple experiments are sufficient to identify the main relationships between topography and ice-cap behaviour. But it is important to be aware of the key assumption. Forcing by a stepped change implies an instant mismatch with initial conditions, which in turn means that the effect of any non-linear relationship is emphasised more than if the rate of change is gradual. For example, the relationship between mass balance and altitude is non-linear, in that the ablation-dominated lower part of the curve is steeper than the higher-altitude part of the curve influenced mainly by accumulation. This means that a stepped change in massbalance forcing will emphasise two effects. First, it will result in an unrealistically rapid response of the ice cap to change; secondly, it will accentuate the asymmetry whereby an ice cap responds more quickly to warming (dominated by ablation at low altitudes) than cooling (dominated by changes in accumulation at higher altitudes). It follows that in the experiments the use of model years is only a guide to the sequence and relative length of the stages of growth and decay. Model years have little significance in absolute terms. There is a further, third implication following from the use of a stepped change in the forcing function. It is that a relatively small change might be amplified over time to create widely different stable states of the ice cap. In the more complicated conditions of the real world it is likely that the initial change would have to be much larger to have the same effect. Thus the experiments indicate no more than the minimum changes in forcing required to move the ice cap from one stable state to another.

The model does not allow for the effects of isostasy. Sensitivity tests show that isostatic compensation plays a relatively subdued role in Patagonia mainly because the ice cap covers the mountain range only thinly. This means that changes in ice thickness are small in relation to changes in ice extent. The main effect of including isostatic compensation beneath a growing ice mass is to slow down the build-up of ice and to accommodate greater ice thicknesses, but without changing ice surface elevations. Since the latter are the main focus of the experiments in this paper, the exclusion of isostasy is unlikely to affect the main conclusions.

\section{DESCRIPTION OF MODEL RESULTS}

Figure 3 shows the extent and surface altitude of the ice cap during its growth and decay. The initial stages of growth are mapped at 1000 model-year intervals; the middle and later parts of the cycle are shown at longer intervals. Initially there are five growth centres, the uplands of the existing ice fields and two centres in the north (Fig. 3a). Most growth is westwards towards the precipitation source. HPS grows fastest, and by 5000 model years it has reached the coast and is contiguous with HPN. Ice then expands up and down the axis of the Andes, mainly on the western flank of the main chain. Ice from the northern ice centre at $42^{\circ} \mathrm{S}$ and ice from the southern centre over HCD both reach the coast 

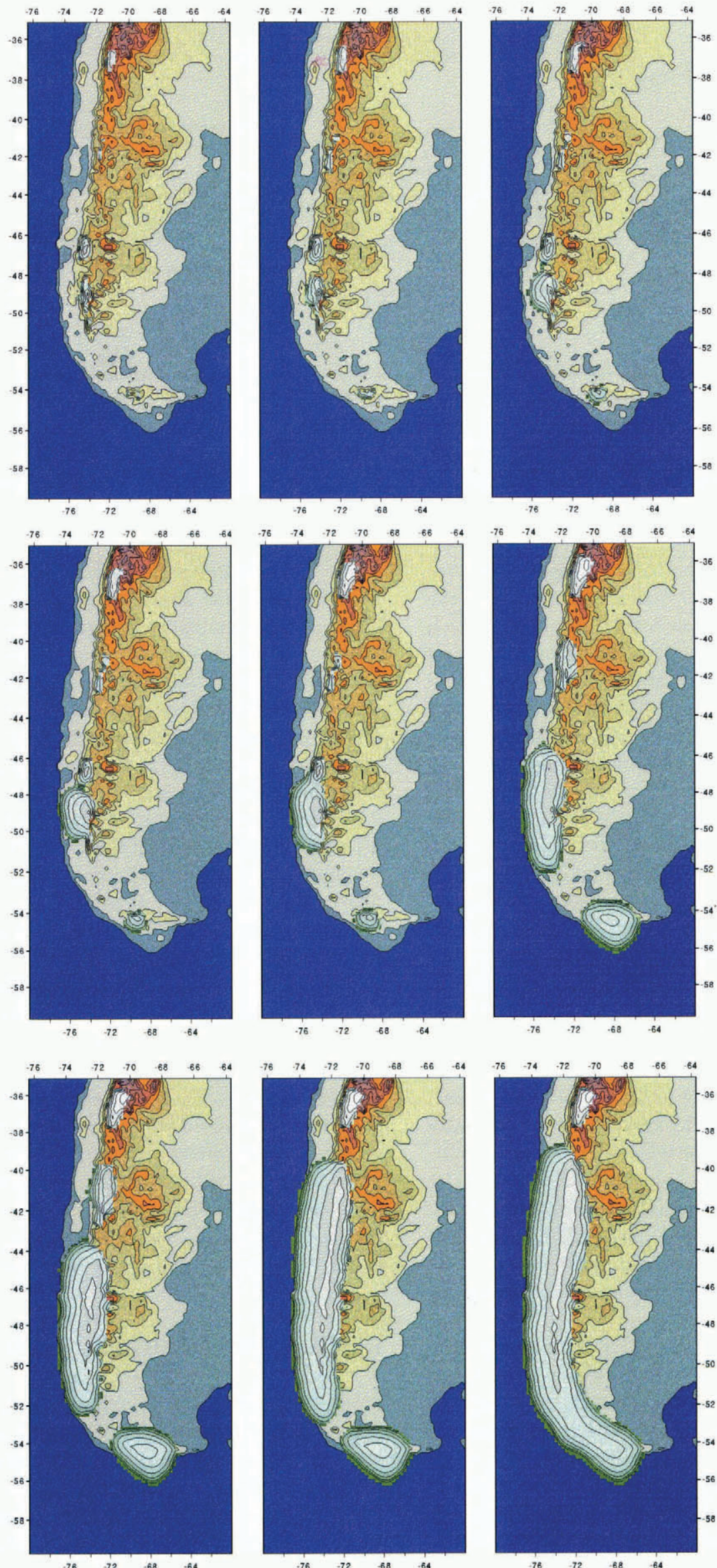

LAND
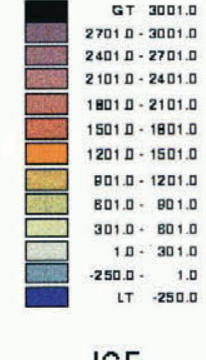

ICE

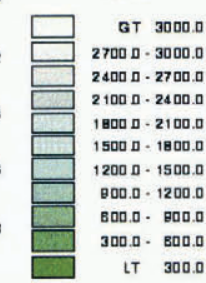

Fig. 3. Maps showing the changing extent and surface altitude $(m)$ of the Patagonian ice cap during a simulated glacial cycle. (a) Growth stages after 1000, 2000, 3000,4000, 5000, 10 000, 15000 and 25000 model years. Ice grow th is initiated by a lowering of the ELA, deglaciation by a rise in the ELA. Variation of the ELA with latitude is shown in Figure 2. 

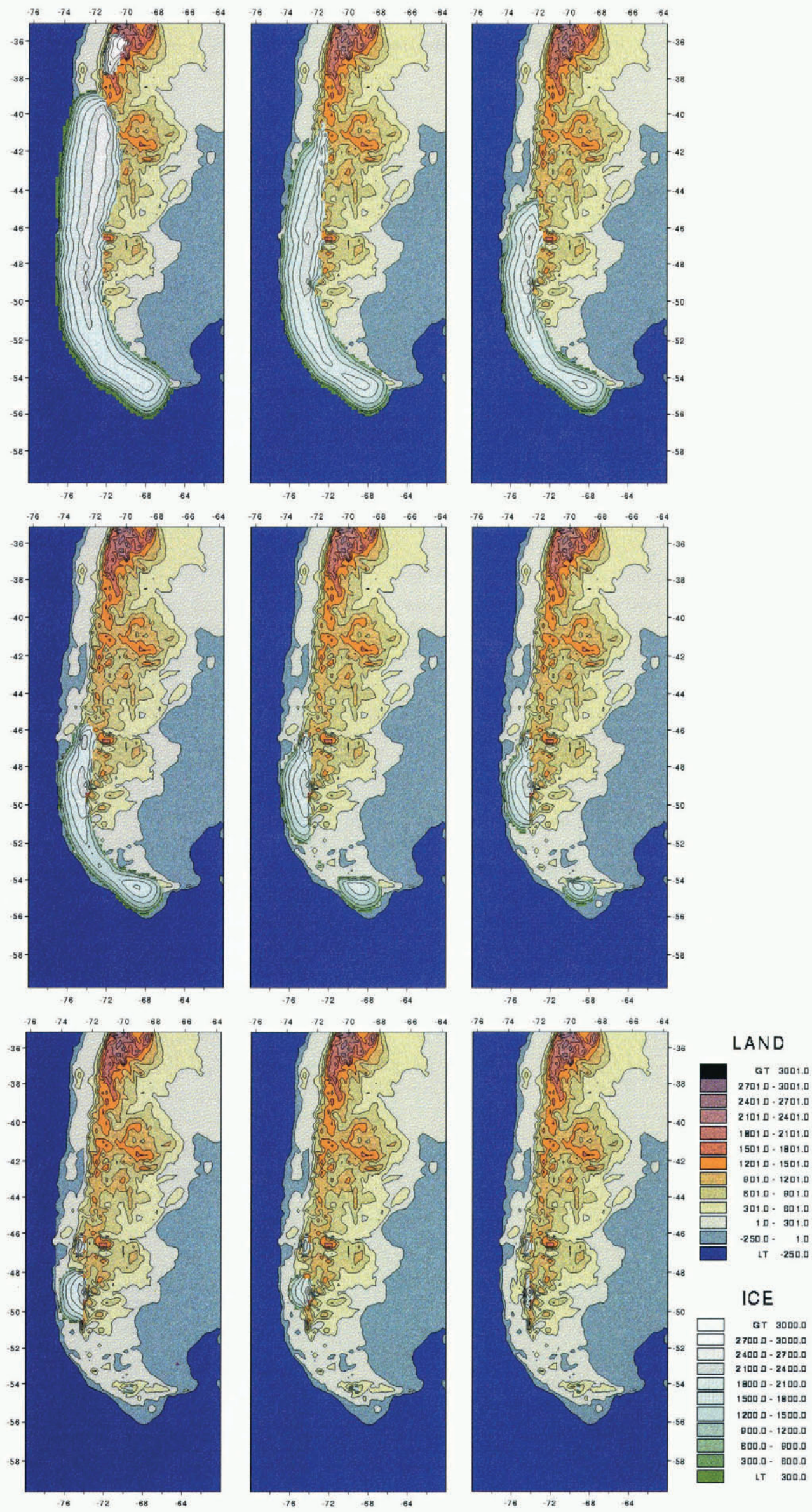

Fig 3(b) Decay of the ice cap. Starting with the maximum at 25000 model years (top left), stages of decay are shown after a further 1000, 2000, 3000, 4000, 5000, 7000, 9000 and 15000 years. 


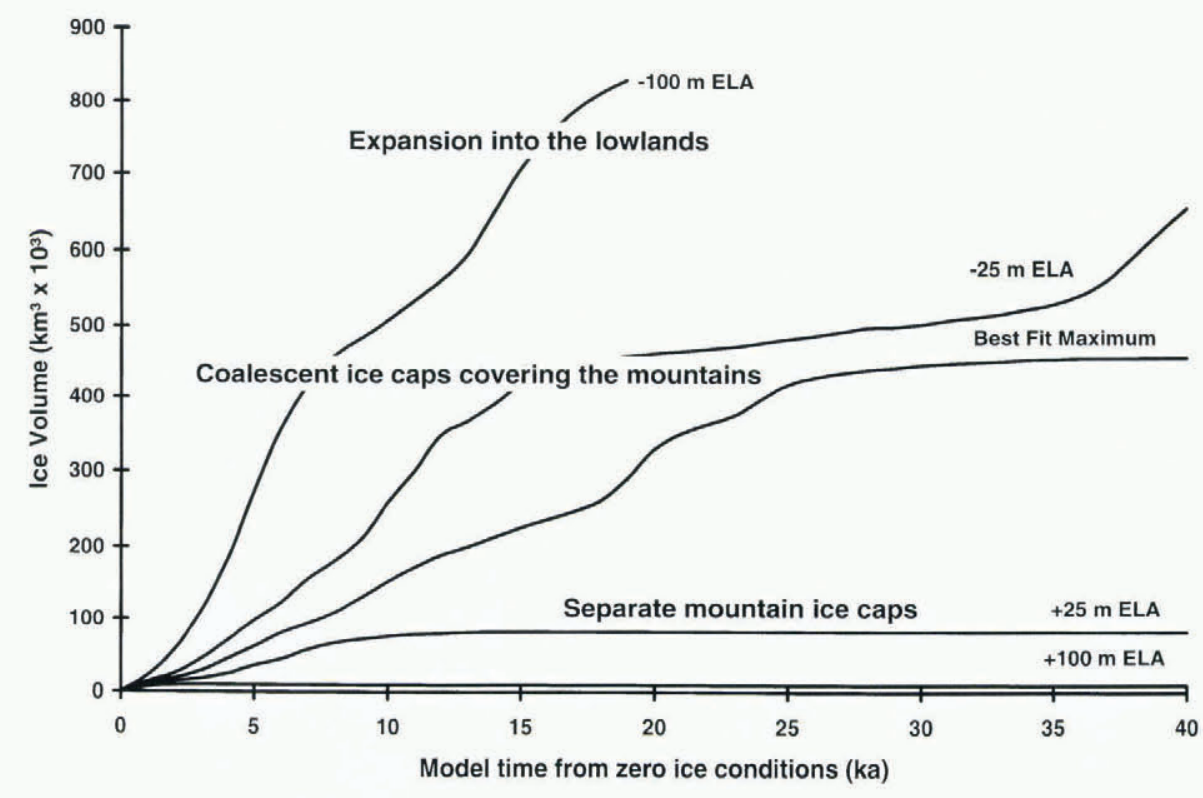

Fig. 4. Changes in ice volume during the growth part of the cycle. Different levels of forcing produce ice caps of markedly different size. ELA differences are in relation to that used to create the best-fit-maximum model (Fig. 3).

and begin a comparable expansion along the western front of the Andes. By 20000 model years the northern centre has coalesced with the combined mid-latitude ice centres. Finally, by 25000 model years the southern centre coalesces with the others, as a ridge of ice builds up over the relatively low topography of the Strait of Magellan. At this stage the ice cap has achieved its equilibrium extent and its volume stabilises, as shown by the best-fit-maximum model run (Fig. 4). The centre in the far north $\left(37^{\circ} \mathrm{S}\right)$ remains separate.

The pattern of retreat is shown in Figure $3 \mathrm{~b}$. Decay is much more rapid and takes place first by the retreat of the northern reaches of the ice cap and only later by a break-up into independent centres. After 1000 model years the ice has cleared the Chilean lake district in the north, and after 2000 model years it has cleared the Golfo Corcovado. At such a stage the ice cap is still intact in the south and has only retreated a little from its margins. At this early stage there is no ice left in the upland growth centre at latitude $42^{\circ} \mathrm{S}$.
After 4000 model years the main southern ice cap has been breached in the vicinity of the Strait of Magellan, and ice retreats towards the combined centre of the HPN and HPS and the southern centre of HCD. The independent ice caps continue to decrease in size but at a progressively slower rate. After 7000 model years HPN has parted from its southern neighbour, but it requires a further 3000-5000 years before the ice fields withdraw to their present size.

There is an asymmetry between the growth and deglaciation limbs of the cycle (Fig. 5). Progressive growth is interrupted by bursts of more rapid change. The volume increase is at a maximum when the saddles between independent centres are being filled. The last burst of growth is associated with ice filling the breach of the Strait of Magellan. As explained above, there is little significance in the overall steepness of the curve, since the rate of growth could be doubled with plausible assumptions about mass balance. Decay, once it commences, is exponential. Ice volume de-

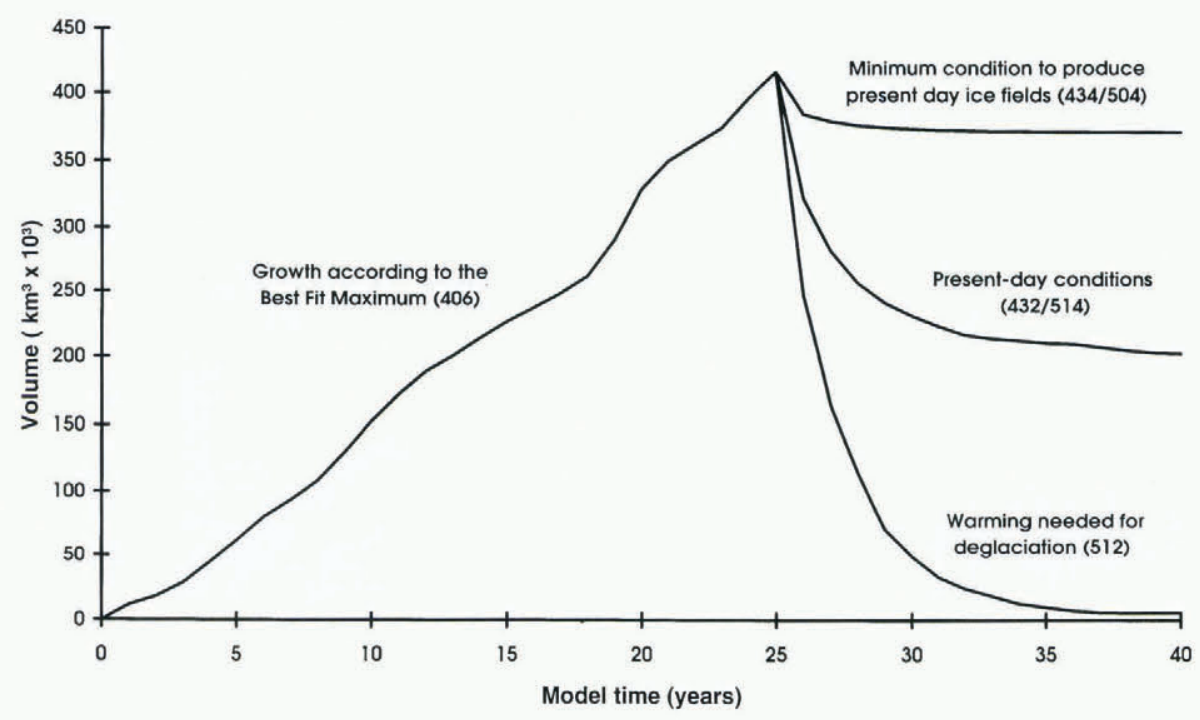

Fig. 5. Changes in ice volume during the cycle. The rising limb is taken from the best-fit-maximum model run. Four alternative deglaciation runs are shown and were applied to the maximum ice-cap morphology. 

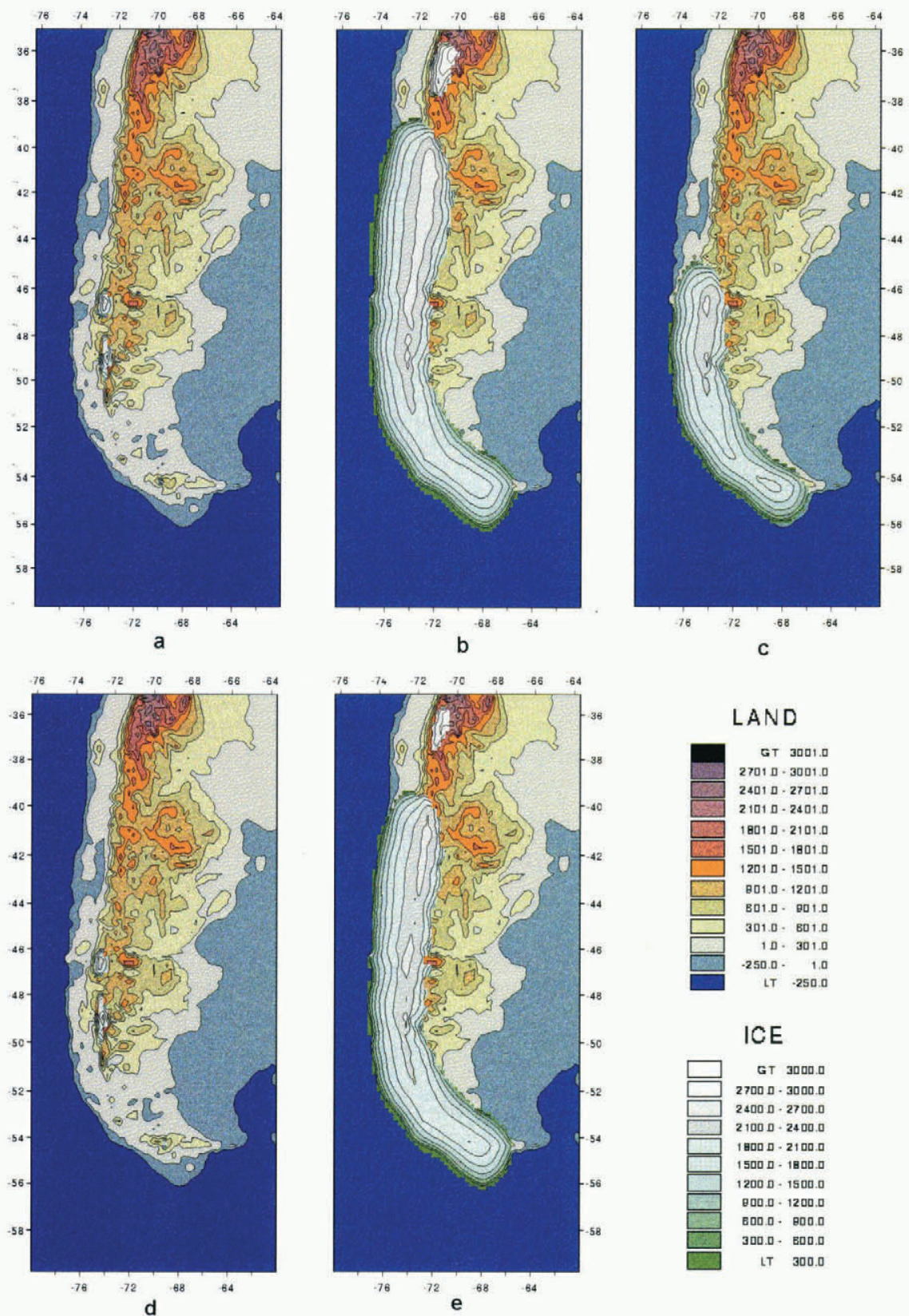

\section{LAND}

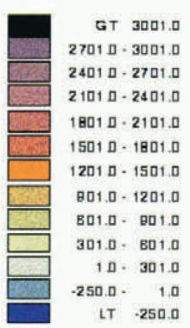

\section{ICE}

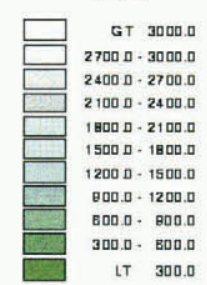

Fig. 6. Contrasting ice-cap configurations which are in equilibrium with the same climate, depending on whether they are on a waxing or waning limb of a glacial cycle. (a) The distribution of small ice fields restricted to the main mountain massifs modelled with ice-free topography and present-day ELA. (b) The modelled maximum ice cap obtained by the best-fit model of Hulton and others (1994). (c) The modelled equilibrium ice cap which results if present-day ELA is applied to maximum ice-cap morphology. (d) The slightly expanded distribution of small ice fields restricted to the main mountain massifs; these modelled glaciers are in equilibrium with climate and produced by the lowest possible ELA consistent with the distribution of present-day ice fields (see Fig. 2). (e) The slightly smaller "maximum" ice cap which results if the lowest possible ELA consistent with present-day ice fields is applied to the maximum ice-cap morphology.

creases most rapidly when breaches appear in the main icecap crest-line, and slows down as the residual centres withdraw into the uplands.

One interesting result is that it is necessary to raise the ELA above present values in order to remove the ice cap (Fig. 2). This is also illustrated in Figure 5 which shows deglaciation under different scenarios. Conditions need to be significantly warmer and/or drier, if the present ice fields are to be reduced to their present size.

Before discussing these results it is important to gain a perspective on their reliability. Sensitivity tests on the model show that the main latitudinal and topographic patterns are stable and common from run to run Hulton and others,
1994). Examples of the volume changes during growth are shown for other model runs with ELAs both higher and lower than that of the best-fit-maximum run (Fig. 4). These show that there is stable state similar to that of the present day and to one when the ice cap attains a volume of around $440000 \mathrm{~km}^{3}$. Eventually, however, stronger forcing causes further ice growth, the volume depending on the level and duration of forcing.

The ice-volume changes point to two conclusions. First there is a threshold effect. Ice caps of similar volumes tend to exist for a range of forcing conditions up to a certain threshold. Once such a threshold is passed, ice caps of markedly different ice volumes become stable. Secondly, the 
widely different responses to quite modest forcing show that the model is highly sensitive to mass-balance-altitude relationships. This means that the model is suitable only for study of the structural relationships in the ice-cap system. Quantitative estimates such as those of timing and rates of growth and decay are only indicative.

\section{DISGUSSION}

In spite of the relative simplicity of the numerical model, the many assumptions needed to make it work and its obvious sensitivity to mass balance, it does contribute useful insights into some of the processes affecting the behaviour of the ice cap through a cycle of growth and decay. One implication of the runs in Figure 4 is that the modelled ice cap reaches some sort of equilibrium when it achieves a volume of $\sim 440000 \mathrm{~km}^{3}$. This occurs when the ice cap occupies its full latitudinal span along the mountain chain and flows into the lowlands on either side. Once it is bounded by a marine calving margin in the west and subject to intense ablation in the relatively warm lowland climates of the east, it is difficult for it to grow without much sharper or longer forcing. Interestingly, this modelled equilibrium state is very similar to the extent of the ice cap at the Last Glacial Maximum (Fig. 1). Also, the clustering of late-Quaternary moraines at the mountain front, as in the Chilean lake district, suggests that such a state occurred on several occasions.

The implication of the match between model predictions and empirical evidence is that there is a stable maximum state achieved by the Patagonian ice cap during glacial episodes. The main reason seems to be the presence of a mountain range of sufficient altitude to accumulate snow, bounded on each side by conditions which favour strong ablation.

A further implication of Figure 4 is that there are two equilibrium states for the ice sheet, separated by a fine climatic threshold. In one, the best-fit-maximum run, the ice cap occupies its Last Glacial limits. In another, with a lowering of the ELA by only $25 \mathrm{~m}$ less, the ice remains in its current mountain centres. This implies that the topography of the mountain chain introduces a threshold; on one side of the threshold there are glacial conditions similar to those of today; on the other there are full glacial conditions. It is probable that the model represents the real-world situation and that the predicted behaviour is a response to the topography of the Andes. Under present conditions ice fields occur on discrete mountain massifs rising above the general level of the mountain chain. A relatively modest lowering of the ELA brings much larger mountain collecting areas into the accumulation area and permits extensive build-up of ice. As the altitude of the ice surface rises there is a feedback effect which increases accumulation until the ice cap reaches its next stable position. This represents an effect long associated with upland areas close to the glaciation limit (Ives and others, 1975).

Nonetheless it is important to add that in the case of the Patagonian ice cap the model is based on two key assumptions and that these influence the clarity with which the two stable states are distinguished. The first assumption is that the ice cap does not alter the position of the ELA or the mass-balance field as it grows and decays. This is important to consider in the case of the large ice sheets that built up in the Northern Hemisphere. However, the assumption seems justified in the case of Patagonia since the ice cap is narrow, remains centred on the axis of the Andes and has relatively little effect on the overall altitude of the mountain barrier as it grows and decays. The main change to the mass-balance field is an increase in the west-east mass-balance gradient (Hulton and Sugden, 1995). The second assumption is the stepped forcing which, as discussed earlier, has the effect of accentuating any ice-cap response. More gradual forcing over shorter time-scales would reduce the sharpness of the threshold. But, even bearing such qualifications in mind, there seems no reason to doubt that the model points to a distinctive tendency of ice-cap behaviour. Thus we conclude that neither of the two assumptions affects the main thrust of the argument, namely, that there is a threshold separating two stable states which is a function of the topography.

This threshold has a different effect on ice-cap stability depending on the direction of change, i.e. whether conditions relate to the waxing or waning limb of a glacial cycle. This means that an identical climate can produce a very different ice-cap morphology, depending on whether the ice cap is building up or decaying. This is illustrated by the experiments in Figure 6. In the first experiment the model is run from an ice-free topography with the present-day ELA. As expected, ice builds up in the locations presently occupied by HPN, HPS and HCD (Fig. 6a). Ice extent achieves a stable equilibrium with climate within 2000 model years. When an identical ELA field is applied to the maximum ice cap (Fig. 6b), the ice decays in the north but stabilises at approximately half its full glacial volume and survives as a large ice cap in the south and centre of its former domain (Fig. 6c). The volume of ice remaining in equilibrium with climate is vastly different in the two scenarios. Starting with an ice-free topography, the equilibrium volume is only $20 \times 10^{3} \mathrm{~km}^{3}$. Starting with the maximum ice cap, the volume stabilises at around $200 \times 10^{3} \mathrm{~km}^{3}$.

The second experiment is even more remarkable. Here we start with an ice-free topography and apply the lowest possible ELA which is consistent with the existence and size of the present-day ice fields (Fig. 2). As before, equilibrium is achieved within 2000 model years (Fig. 6d). If this same ELA is applied to the maximum ice cap, there is only a minor loss of volume and the full glacial ice cap is able to thrive in a climate which is only slightly wetter and/or cooler than today (Fig. 6e). In this case the contrast between the two equilibrium states is increased. The volumes are less than $50 \times 10^{3} \mathrm{~km}^{3}$ starting from an ice-free topography, and about $360 \times 10^{3} \mathrm{~km}^{3}$ starting with the maximum conditions. Again the two equilibrium states are widely divergent and yet they coexist with identical climate but different starting conditions.

Moraines in the lowlands show that there are conditions under which the ice cap can extend beyond the mountain realm (Fig. 1). These show that ice extended over the eastern plains of Patagonia as far as the Atlantic (Caldenius, 1932; Clapperton, 1993) and into the western lowlands in the northern lake district (Porter, 1981). Presumably, such expansion requires either stronger or longer forcing or a combination of the two. Ice extent will be a trade-off between accumulation at higher altitudes on the ice surface and ablation in the lowlands. The longer and more severe the forcing, the greater the ice extent will be. The experiments in Figure 4 suggest that the extra forcing required, compared to the best-fit-maximum run, is equivalent to a lowering of the ELA by a further $\sim 100 \mathrm{~m}$. Perhaps this could be a simul- 
ation of early-Quaternary ice caps. Although other factors such as tectonics will be involved, a spread of limits would be expected in a lowland, reflecting the degree of climatic forcing involved.

One suggestive result of the modelling is that, whereas only modest ELA lowering is necessary to grow the ice cap, considerably more of an ELA rise is required to remove it. There are several possible reasons for such asymmetry. One possibility is that the present-day ELA has been underestimated and is lower than suggested by the modelling. Another is that the mass-balance parameterization is improperly defined in the model. But, in spite of such reservations, the model has survived several stringent simulation tests and it is likely that it points to a real qualitative effect. If so, this is another reflection of the stability of the equilibrium state when the ice occupies its full glacial span. The only way it can decay is when surface ablation rises to levels above those of today in order to compensate for the extra accumulation falling onto an ice-cap surface higher than that of the ice fields today. Thus it makes sense to argue that a warmer and/or drier climate was necessary to initiate deglaciation.

\section{CONCLUSIONS}

The main significance of these modelling experiments is that they suggest there is no simple link between ice extent and climate in the case of the Patagonian ice cap. The presence and morphology of the Andes introduces a topographic threshold which favours two stable states to which the ice cap tends to converge. One of these is akin to the present patchy distribution of ice fields, while the other is a continuous ice cap aligned along the crest of the Andes over a distance of $1800 \mathrm{~km}$. What is interesting is that either of the two stable states may be achieved under the same climate and that a minor change of climate can cause the ice cap to change from one to the other state. Clearly, such a finding suggests caution when relating particular glacier states to global climate and ocean conditions. In addition, the sensitivity of the ice cap varies according to the ice-cap history and the trajectory of change; a smaller pertubation in climate is needed to cause the ice cap to grow from its minimum to its maximum state than vice versa.

The cause of the non-linear behaviour seems to be related to the presence and morphology of the Andes. A relatively small change in climate allows ice to build up in the mountains. Assuming an elevation increase above the level of the main mountain range, feedback processes then cause the increasing elevation of the ice to increase the mass balance and build up the ice cap rapidly. Once a continuous high ice-cap ridge is formed, a warmer and/or drier climate than today is required to cause deglaciation.

There are three specific conclusions arising from this work:

1. The growth and decay of the Patagonian ice cap illustrates non-linear behaviour due to topographic effects.

2. The relationship between ice volume and climate varies according to the direction of change and is thus different on the waxing and waning limbs of a glacial cycle.

3. There is asymmetry between the perturbation needed to grow an ice cap to its Last Glacial Maximum extent and that needed to remove it.

\section{ACKNOWLEDGEMENTS}

We gratefully acknowledge the support of the U.K. Natural Environment Research Council (GST/02/544). D.E.S. is also grateful for support from the Leverhulme Trust.

\section{REFERENCES}

Ahlmann, H.W:son. 1948. Glaciological research on the North Atlantic coasts. London, Royal Geographical Society. (Royal Geographical Society Research Series 1. .

Bentley, M. 1996. Lake shore moraines, Chilean Lake District. Earth Surface Processes and Landforms, 21 (6), 493-507.

Caldenius, C. C. 1932. Las glaciaciones cuaternarias en la Patagonia y Tierra del Fuego. Geogr. Ann., 14(1-2), 1-64.

Clapperton, C. M. 1993. Quaternary geology and geomorphology of South America. Amsterdam, Elsevier.

Hubbard, A. 1997. Topography and palaeoglacier fluctuations in the Chilean Andes. Earth Surface Processes and Landforms 22 (1), 7992.

Hulton, N. R. J. and D. E. Sugden. 1995. Modelling mass balance on former maritime ice caps: a Patagonian example. Ann. Glaciol., 21, 304310.

Hulton, N., D. Sugden, A. Payne and C. M. Clapperton. 1994. Glacier modeling and the climate of Patagonia during the last glacial maximum. Quat. Res., 42 (1), 1-19.

Huybrechts, P. 1993. Glaciological modelling of the Late Cenozoic East Antarctic ice sheet: stability of dynamism? Geogr. Ann., 75A (4), 221-238.

Ives, J. D., J.T. Andrews and R. G. Barry. 1975, Growth and decay of the Laurentide ice sheet and comparison with Fenno-Scandinavia. Naturwissenschaften, 62 (3), $118-125$.

Kerr, A. and D. E. Sugden. 1994. The sensitivity of the south Chilean snowline to climate change. Climatic Change, 28 (3), 255-272.

Lowell, T, V. and 8 others. 1995. Interhemispheric correlation of late Pleistocene glacial events. Science, 269 (5230), 1541-1549.

Miller, A. 1976. The climate of Chile. In Schwerdtfeger, W., ed. Climates of Central and South America. New York, Elsevier, 113-145. (World Survey of Climatology 12.)

Oerlemans, J. 1988. Simulation of historic glacier variations with a simple climate glacier model. f. Glaciol., 34(118), 333-341.

Payne, A.J. and D. E. Sugden. 1990. Topography and ice sheet dynamics. Earth Surface Processes and Landforms, 15 (7), 625-639.

Porter, S. C. 1981. Pleistocene glaciation in the southern Lake District of Chile. Quat. Res., 16 (3), $263-292$. 